\title{
A Study on Visual Scaffolding Design Principles in Web-Based Learning Environments
}

\author{
Soyoung Park \\ Education Research Institute, Seoul National University, Korea \\ mellowmarie@snu.ac.kr
}

\begin{abstract}
Visual scaffolding, a type of scaffolding provided in a visual format, is considered to have potential in web-based learning environments as it naturally includes tacit information, highlights the critical features of tasks and promotes learning through the spatial organization of tasks. However, systematic approaches to visual scaffolding design principles are rare. This study aims to develop visual scaffolding design principles and guidelines in a web-based learning environment through a literature review. The specific visual scaffolding design principles regarding objects are 1) the spatial organization of information, 2) coaching, modelling, and mentoring, 3) explication of the task structure, 4) explication of the process, 5) explication of the cognitive process, 6) explication of understanding, 7) metacognitive prompts. In terms of visuals, the principles drawn are 8) ensuring visibility, coupling, and usability, 9) the use of appropriate visuals, 10) proximity and simplicity of the display, 11) spatial organization of the toolset. The principles regarding the learners are 12) consideration of different learners, and 13) manipulation of support and use. The limitations and future research directions are discussed.
\end{abstract}

Keywords: visual scaffolding design, visual scaffolding design principles, scaffolding design in web-based learning environments, learning design, web-based learning

\section{Introduction}

Scaffolding is a frequently used strategy to facilitate learning by enabling learners to accomplish tasks that would be beyond their capacity if unassisted. Since its introduction by Wood, Bruner, and Ross (1976), the notion of scaffolding has been used as a metaphor for the process by which a more knowledgeable person guides novices' learning, progressing learners' development from an interpersonal plane to an intrapersonal plane (Pea, 2004; Vygotsky, 1962). Moreover, technological advancement has led to the invention of different types of technology-based scaffolding (Pea, 2004). As learning actively occurs in software-based environments, scaffolding tends to be embedded in the formal mechanism of specific software to facilitate learning and performance by aiding the process structure (Guzdial, 1994). In many cases, such web-based scaffolding is provided through conversational devices, such as verbal questions, textual explanations or feedback from an instructor or a software system.

However, neither the textual nor visual forms of scaffolding in web-based environments are known to be inherently better or worse than the other forms because diverse forms, means, and types of scaffolding have strengths and limitations, and the inclusive use of various scaffoldings produces more synergistic effects on learning (Sharma and Hannafin, 2007). According to Quintana, Krajcik, and Soloway (2002), visual scaffolding, such as graphical scaffolding, may be more effective, powerful, and motivating, although it may be misleading if designed with less caution. Although textual scaffolding is sometimes used effectively by learners, it is often bypassed due to its textual nature. Furthermore, providing multiple and adaptive support through diverse means and forms of scaffolding in web-based learning is believed to synergistically support and adaptively meet the varied needs of learners (Bull, et al, 1999; Park, 2019; Park and Rha, 2018; Shadiev, Hwang, and Liu, 2018; Tabak, 2004). For example, visual scaffolding is an equalizer in terms of individual learning styles because it diversifies representational forms of knowledge.

This study aims to compile design principles and guidelines for visual scaffolding in web-based learning environments. Previous research investigating visual scaffolding in web-based environments highlights the effectiveness and significance of the various forms of visual scaffolding as instructional strategies by providing explicit or tacit hints (e.g., Quintana, et al., 2002), promoting cognitive and metacognitive processes (e.g., Cuevas, Fiore, and Oser, 2002), and conclusively improving learners' academic achievement (e.g., Alibali, 2006; Alibali and Nathan, 2007), higher-order thinking and problem solving (Lim, Song, and Lee, 2012; Lin and Dwyer 2004; Park, 2016, 2019; Park and Rha, 2018; Rha and Park, 2010; Shadiev, Hwang, and Liu, 2018). 
Still, despite the various studies regarding visual scaffolding in web-based learning, how to design visual scaffolding in a systematic manner remains unknown. This lack of research hinders the active and effective use of visual scaffolding in learning (Park, 2017).

Therefore, the guidance regarding how to embed visual scaffolding in web-based learning environments could be useful and practical in order to contribute to more effective, efficient, and attractive learning.

\section{Methods}

This study involved searching the literature, selecting relevant articles (Creswell, 2009; Creswell and Clark, 2017), drawing implications from the reviewed literature, classifying those implications, and developing design principles and guidelines according to the methodology proposed by Reigeluth (1983). During the search and selection phase, relevant articles were sought and selected using the literature review methods described by Creswell (2009), Creswell and Clark (2017), and Hart (2001, 2018). Based on a preliminary reading, a set of keywords, including scaffolding, web-based scaffolding, visual learning, visualization, information visualization, visual scaffolding, and scaffolding design, was identified. Using these keywords, the relevant literature was found in appropriate databases, such as the Seoul National University Library, which includes ERIC, the Social Science Citation Index and a wide range of other academic databases, and Google Scholar for a broad search. Among the results, significant studies were selected in accordance with the criteria of authority, seminality, and relevancy (Hart, 2001, 2018). During the review of the selected studies, cited references were selected for focused review. This focused search was repeated with a broad search. This repetition allowed the search to proceed from general to specific and from classic to recent works until saturation was achieved. Implications were drawn from the reviewed literature, and the principles were categorized (see Figure 1).
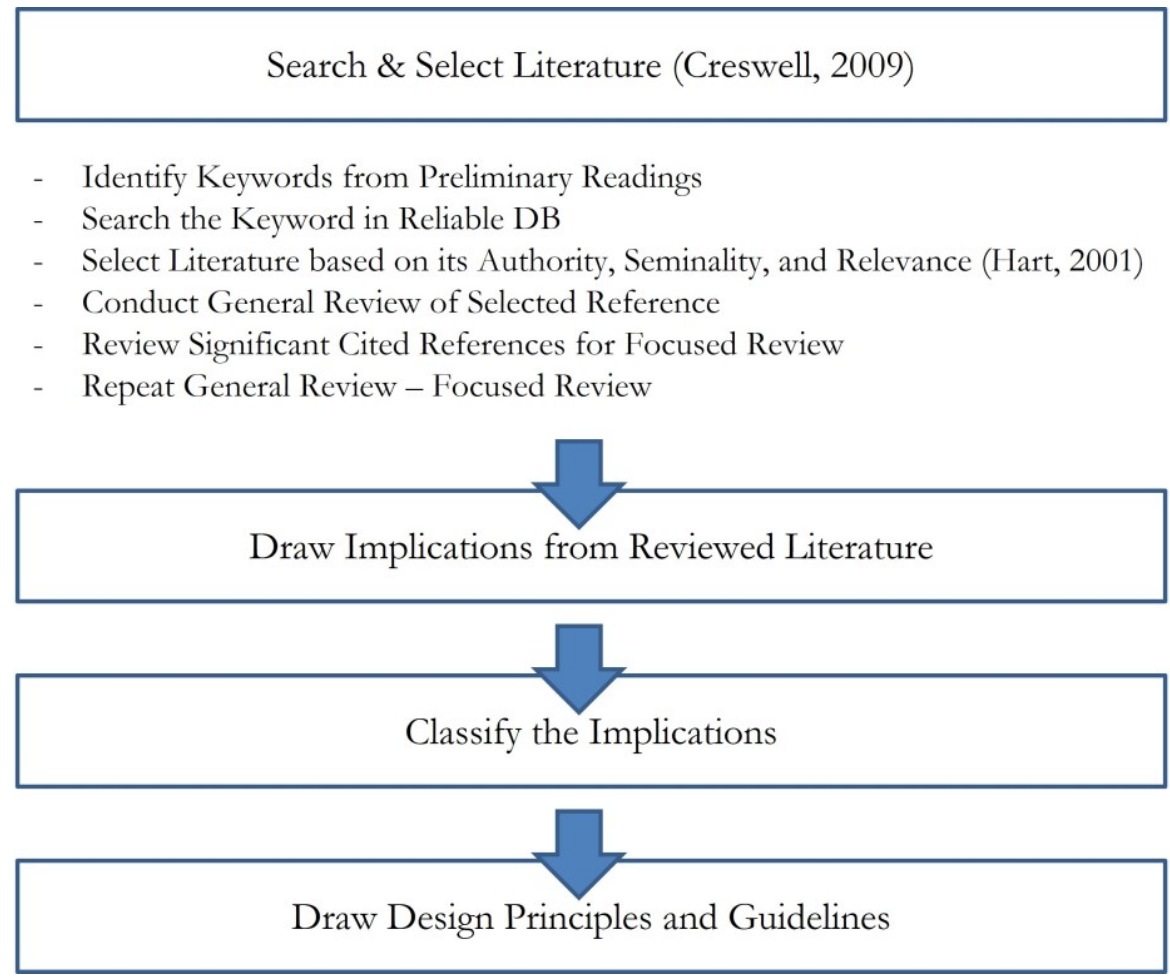

Figure 1: Methodology Used for the Construction of a Set of Design Principles

The literature is classified into visual scaffolding concepts and characteristics, information visualization, visual scaffolding design, scaffolding design in web-based environments, effects of visual scaffolding, and visual scaffolding design principles and guidelines. Studies investigating the concepts and characteristics of visual scaffolding and visuals in learning provided the theoretical basis. Studies regarding information visualization, scaffolding design in web-based environments, and visual scaffolding design provided more practical guidelines to build a set of design principles. The literature concerning information visualization provided guidelines regarding how to visualize and work with information for visual scaffolding. Studies concerning scaffolding design in web-based environments guided the design of visuals for scaffolding functions. Previous research investigating visual scaffolding design was rare but provided more practical guidelines regarding the 
construction of a set of visual scaffolding design principles in web-based environments. A relatively small number of studies addressed visual scaffolding design in web-based learning environments; thus, it was necessary to draw implications from the literature concerning information visualization, scaffolding design in web-based environments, and visual scaffolding design in general contexts. In addition, although this study aimed to examine visual scaffolding design in web-based environments, borderline cases, such as visual scaffolding design or information visualization in offline learning environments, were also included to draw more implications from related fields.

\section{Studies concerning visual scaffolding}

\subsection{Concepts and characteristics of visual scaffolding}

Visual scaffolding is realized as a form of conceptualized visual artefacts. The shape can be with or without text and 2D or 3D (Park, 2017; Rha and Park, 2010) with the aim of providing learners with focused and effective learning or problem-solving. The concept of visual scaffolding originated from the concept of visualization, and the fundamental mechanism of visualization is the formation of visual representations of concrete visual objects and abstract meanings (Rha, 2007; Rha, Choi, and Choi, 2009). The concept also stems from the idea of scaffolding, i.e., providing a process structure and strategic hints for learners to aid in task completion and prevent motivation loss.

According to Rha and Park (2010), visual scaffolding has the potential to improve learning in three ways. First, visual scaffolding naturally provides more tacit information to learners. A visual image inherently delivers additional information through its shape, space, direction, structure, relationship, size and colour. Although not written in verbal terms, pieces of information are scattered and naturally included in visual scaffolding, thereby providing richer supplementary information to learners. Second, visual scaffolding tends to encourage learners to achieve a structural understanding of tasks with a lower cognitive load largely because visual scaffolding provides learners with spatial representations of both declarative and procedural knowledge. Learners can understand a particular knowledge structure effortlessly if provided with a spatial representation of the task structures (Schwartz and Heiser, 2005). This type of external spatialization of tasks may help learners form an internal structure of tasks (Jonassen and Hung, 2006). Moreover, learners might experience more insightful perspectives, obtain a more in-depth understanding, and develop higher-order thinking and problem-solving skills (Buzan, 1994; Okebukola, 1992; Schwarts and Heiser, 2005). Third, visual scaffolding can highlight the critical features of a task because visual scaffolding can be a more powerful affordance due to its visual nature, thereby attracting and directing learners' attention. For example, representational and interpretive visuals can visually re-phrase and emphasize parts of textual explanation in various ways.

Visual scaffolding can be classified into representational, organizational, interpretational, and transformational functions (Carney and Levin, 2002). First, visual scaffolding might support learners by providing a pictorial illustration that mirrors a part or all of the text content, thereby elaborating content knowledge. A typical example can be easily found in English-mediated instruction for students who are non-native English speakers (e.g., Gibbons, 2008; Hassett and Schieble, 2007). Second, visual scaffolding might facilitate learning by providing a structural framework for the content. For example, showing a series of steps or a structural map of the text contents can be considered organizational visual scaffolding. Visual scaffolding has often been used to enable learners to understand the macro structure and process of learning by providing structural figures (e.g., Quintana, et al., 2002; Rha and Park, 2010) or forming learners' psychological schemata (e.g., Coombs, 2006), providing both procedural and strategic help with content knowledge, knowledge of strategy and metacognition. Third, visual scaffolding aids learners through its explanatory or analogous functions. Regarding the explanatory functions of visual scaffolding, pictures depicting each part and step of a mechanism or system (e.g., Cuevas, et al., 2002) and a visual analogy of the content knowledge (e.g., Carney and Levin, 2002) can be provided, encouraging learners to understand the knowledge from diverse perspectives and think more insightfully and creatively. Finally, visual scaffolding might function as a mnemonic utilizing the association between the visual and problem-solving process or structure (e.g., Rha and Park, 2010).

These diverse functions of visual scaffolding are based on Paivio's $(1971,1986)$ dual coding theory. According to Paivio $(1971,1986)$, humans perceive and encode information through both verbal and visual channels, and the verbal and visual systems are stored in long-term memory through referential connections. This dual processing of information optimizes the use of the limited working memory. Furthermore, learners are known to construct their understanding of how things work and what could occur following an action by interpreting 
the visual structure of objects (Norman, 1986). Such a mental model is formed through experience, training, and instruction rather than developed inherently (Norman, 1988). Empirical research also shows that providing both verbal and visual information is effective for learning in practice (e.g., Mayer, 2001; Mayer and Anderson, 1991, 1992; Mayer, et al., 1996).

\subsection{Studies concerning the effectiveness of visual scaffolding in learning}

Visual scaffolding is frequently employed to visually elaborate content knowledge or the macro-structure of tasks (McKenzie, 1999). Cuevas, et al.'s (2002) research utilizes diagrams as visual scaffolding to catalyse learners' cognitive and metacognitive processes. These authors reported that diagram scaffolding supports learners' mental model formation, thus significantly improving the instructional efficiency in a complex task training environment by diminishing the cognitive load. Moreover, the authors maintain that scaffolding is more effective for the acquisition of integrative knowledge than declarative knowledge. Quintana, et al. (2002) used graphical scaffolding to support learners by providing a large picture or macro structure of science inquiry learning. In their research, visual scaffolding played a decisive role in encouraging the students' metacognition and comprehensive understanding of the task. More importantly, the authors reported that learners' assumptions regarding the specific shapes or forms of given visual scaffoldings functioned as tacit hints about the problem-solving process. The visual scaffolding used in Rha and Park's (2010) research functioned not only as procedural and strategic scaffolding but also as mnemonic scaffolding to support students' memorization and retention of problem-solving processes and structures. Some research also indicates that visual scaffolding nurtures higher-order thinking ability better than verbal scaffolding. For example, Koes and Hanum (2019) demonstrated that visual scaffolding promoted physics teachers' higher-order thinking, helped them understand the concepts of the content and directed and guided them in problem solving. Kidwai, et al.'s (2004) research also indicated that visual scaffolding specifically designed and appropriately employed has the potential to emphasize and illustrate procedural understanding, thus decreasing the cognitive load associated with higher-order thinking. Visual scaffolding is also known to enhance language processing and understanding by providing real-world and common-sense knowledge and grounding actions through the joint processing of language (Alibali and Nathan, 2007; Bernardi, el al., 2019) because visual data that are jointly processed with language contribute to the grounded process and easier language understanding (Bernardi, et al., 2019). Alibali and Nathan (2007) reported that teachers used gestural scaffolding most frequently when presenting new materials, abstract referents, and feedback to students. These gestures were assumed to function as a way to ground the teachers' verbal instruction (i.e., to connect the teachers' verbal explanation with real-world and physical referents), thereby enabling the students to process information through both verbal and visual channels. Visual scaffolding through grounding acts includes pointing and representational gestures. Visual scaffolding has been reported to be effective among language learners because it promotes knowledge comprehension by supplementing verbal information (e.g., Carrier and Tatum, 2006; Coombs, 2006; Gibbons, 2008; Hassett and Schieble, 2007). Visual scaffolding can also foster more collaborative learning and knowledge building among the community of practice by allowing learners to easily share necessary support and feedback (Patarakin, Burov, and Remorenko, 2017). Furthermore, visual scaffolding can enhance integrated spatial and nonspatial visual analytics by providing coordinated views of both spatial and nonspatial views as visual analysis tools (Marai, 2015).

\section{Studies concerning visual scaffolding design}

\subsection{Information visualization in teaching and learning}

Information visualization can be conceptualized as forming visual objects in a way that encourages learners to better understand the content. Information visualization augments cognition by 1) the external storage of information, which frees working memory resources (Hegarty, 2011; Scaife and Rogers, 1996), 2) the organization of information by indexing it spatially (Hegarty, 2011; Larkin and Simon, 1987; Schwarts and Heiser, 2005), and 3) the offloading of cognition on perception (Hegarty, 2011; Scaife and Rogers, 1996; Schwarts and Heiser, 2005). The principles of information visualization have been proposed by numerous researchers. By synthesizing previous studies, the following principles are extracted: 1) the visual information must be relevant to the text content and faithfully depict or overlap with the text content such that the pictures and text provide congruent or supporting information (Carney and Levin, 2002; Davis and Linn, 2000); 2) the visual information must be selected by considering both the desired function, such as representation, organization, interpretation, or transformation, and the desired performance outcomes, including comprehension, memory, and transfer (Carney and Levin, 2002; Mayer, 2001; Oh, 2007); 3) the visual information must be perceived by the learners in the intended manner to be effective in learning (Hegarty, 
2011; Kosslyn, 2017; Mayer, 2001; Oh, 2007; Park, 2018; Tversky, 2002); 4) the visuals should present no more or less information than needed by the learner (Hegarty, 2011; Kosslyn, 2017); 5) the text should be concrete and easy to understand without additional visuals; however, the more difficult the text is to understand, the more that visuals help (Mayer, 2001; Park, 2019); 6) when arranging text, it is crucial to locate the text titles and subtitles on the upper side of the body as a separate header and the body should be grouped by relevant text leaving whitespace among the groups (Kim, 2006; Park, 2019); 7) the visuals need to be proximally located; hence, an integrated display or pop-up display of the visuals may be more effective than split displays (Bentrancourt and Bisseret, 1998; Mayer, 2001); 8) visual information can be more beneficial as text adjunct when learners are directed to perform some activities with the visuals that lead to a controllable product, such as labelling the features of an illustration (Mayer, 2001; Peeck, 1993) or structuring a process (e.g., Rubman and Waters, 2000); 9) regarding learners' cognitive style, visual learners are more adept at remembering pictured objects and benefit more from visual illustrations than verbal learners (Levin, 1980; Levin, et al., 1974; Riding and Douglas, 1993); 10) basic reading skills are prerequisites for learners to benefit from pictures (Mayer, 2001; Oh, 2007); 11) mnemonics should be considered more important for better learning based on mnemonic principles and procedures because mnemonics have impressive beneficial effects on memorization and recall in various text topics and genres (Carney and Levin, 1998; Carney, Levin, and Levin, 1993; Higbee, 1988; Levin, 1980); and 12) the groupings should be based on gestalt principles with features emerging more generally, thereby encoding the fundamental structure in the display (Cheng and Barone, 2017; Hegarty, 2011; Kosslyn, 2017).

\subsection{Scaffolding design in web-based environments}

Studies concerning scaffolding design in web environments mainly emphasize 1) predicting the type of support that is sufficient to enable a student to perform a specific task and 2) distinguishing among students at different developmental levels, exploring how to combine different types of scaffolds, and considering the role of human scaffolding (Pea, 2004).

Quintana et al. (2002) suggested several scaffolding design guidelines for software scaffolding. First, scaffolding and the scaffolding content should be visible rather than triggered by learners. The scaffolding should be initially visible and can be eventually removed if the learners do not need such scaffolding. Second, when provided together with other scaffoldings in a workplace, all scaffoldings should be tightly coupled, enabling learners to focus their attention on all scaffoldings. Third, the scaffoldings need to be designed to appropriately facilitate learners' mindful performance. Finally, neither textual nor graphical forms of scaffoldings are inherently better or worse. Therefore, scaffolding representations can assume any form necessary.

Additionally, strategies regarding the use of scaffolding as a performance support toolset can be proposed to ensure the success of e-learning by providing embedded scaffolding design strategies. Schutt (2003) suggested strategies, including organizing information in chunks to prevent information overload, coaching novices towards expertise, incorporating modelling by demonstrating the desired procedures accompanied by explanations, and providing mentoring. This approach corresponds to cognitive load theory, which emphasizes information chunking and the consequent schema-building of learners.

Scaffolding design strategy can also be drawn from Kao, Lehman, and Cennamo's (1997) elements of scaffolding in terms of integrated media design. Most importantly, considering the metaphor of scaffolding in which knowledge acquisition consists of simple and complex or low and high skills (Bruner, 1973), hierarchical component knowledge or skills need to be considered and reflected upon in software scaffolding. In addition, decreasing the support levels, repetitive authentic practice, and ongoing assessment may be considered in the design of software scaffolding if possible.

Jonassen (1999) noted that scaffolding encompasses the manipulation of a task by the system and suggested the following three separate approaches to scaffolding design: scaffolding facilitates learners' insufficient prior knowledge or readiness by adjusting the task difficulties, restructuring the task to supplement necessary prior knowledge, or providing alternative assessments. Furthermore, the explication of the required activity structure to complete a task is necessary using activity theory or cognitive task analysis. Regarding the use of scaffolding, the different needs and experiences of learners can naturally lead to the selective use of scaffolding. For example, the more experienced the learners, the more they tend to partially apply and adapt necessary guidelines from a set of guidelines; the more novice the learners, the more likely they are to use a 
comprehensive set of guidelines (Chi, et al., 2001; Park, 2016). Thus, the degree of use differs in accordance with the different profiles of the learners.

(6) Scaffolding design principles and guidelines have also been proposed in the context of problem-solving situations in several studies (e.g., Kim and Lim, 2019; Sharma and Hannafin, 2007, Quintana, et al., 2004). These studies propose a more complete and systematic framework for scaffolding design, especially in webbased environments. According to these studies, scaffolding seems to support the cognitive, metacognitive, and affective aspects of learning through supportive and reflective mechanisms that facilitate learners' epistemic beliefs, motivation, and self-direction (Kim and Lim, 2019). Sharma and Hannafin (2007) synthesized previous research concerning scaffolding design and extracted key design considerations and implications for scaffolding. According to these authors, the primary considerations lie in rendering cognitive processes explicit and using appropriate representations. Regarding the rendering of the cognitive process explicit, the implications include 1) explicating processes utilizing procedural scaffolding, such as offering thinking models, thereby reducing the extraneous load, 2) enhancing understanding visibly through metacognitive scaffolding, 3) using procedural and metacognitive scaffolding in balance, and 4) considering learners' characteristics and expectations of tasks. The appropriate use of representations involves 1) the integration of contextually appropriate embedded scaffoldings, 2) the utilization of learner-sensitive scaffolding that considers learners' assumptions, needs, and characteristics, 3) ensuring scaffolding visibility and coupling, and 4) ensuring appropriate modelling by providing process prompts and metacognitive prompts.

Kali and Linn (2008) and Quintana, et al. (2004) proposed meta-design guidelines and key implications for general software design, especially for software scaffolding design related to science inquiry, along with pragmatic principles and examples of their implementation. These studies emphasize the importance of rendering science and thinking visible and promoting self-directed learning in terms of the general process of science enquiry, including sense-making, process management, and articulation and reflection (Kali and Linn, 2008; Quintana, et al., 2004). The guidelines are as follows: 1) use of representations and language to bridge learners' understanding, 2) organization of tools and artefacts around the semantics of the discipline, 3) the use of representations that learners can inspect in different ways to reveal the important properties of the underlying data, 4) providing structure for complex tasks and functionality, 5) embedding expert guidance regarding scientific practices, 6) automatically addressing non-salient, routine tasks, and 7) facilitating ongoing articulation and reflection during the investigation along with strategies for each guideline (Quintana, et al., 2004).

\subsection{Studies concerning visual scaffolding design in web-based environments}

Visual scaffolding in a web-based learning environment can be designed at a simple level, including representational and organizational functions, and at a complex level, including interpretational and transformational functions (Park, 2017; Rha and Park, 2010). For illustration, the explanatory features of visual scaffolding might be closely related to the representative features of visual scaffolding as both features faithfully "re" present verbal or textual information in a visual form utilizing pictorial illustration. Similarly, the organizational features faithfully reflect the knowledge structure. However, the analogous features and transformational/mnemonic features of visual scaffolding might be distinguished from such simple-level functions because visual analogies and visual mnemonics do not faithfully or simply mirror the verbal or textual information. Visual analogies and visual mnemonics both undergo a process to transform specific verbal or textual information into visual shapes.

Furthermore, visual scaffolding design needs to consider conceptual, procedural and strategic, and metacognitive functions to realize sense-making, process and structure, and articulation and reflection, respectively (Hannafin, Land, and Oliver, 1999; Hannafin, et al., 2001; Quintana, et al., 2004). First, visuals, such as still pictures, animations, or graphics, can be used to highlight and elaborate upon the central features of content knowledge. In contrast to text-only presentations, various types of visuals can be used to structuralize and chunk conceptual knowledge. Second, visual scaffolding can be procedural in terms of either the content knowledge or the knowledge of strategy, thereby channelling and focusing learners' attention to goals through appropriate processes. Specifically, visual scaffolding can clarify the following step and how to navigate through the proper steps in learning (e.g., Quintana, et al., 2002; Rha and Park, 2010). Third, visual scaffolding can provide a cue or hint regarding alternative ways or approaches to achieve a goal, available tools and resources, or strategic guidance at critical phases during learning (Rha and Park, 2010). Fourth, to help learners discover "how to think" in learning, metacognitive visual scaffolding can remind learners to 
reflect upon goals or prompt them to relate the specific resource or outcome to the problem or task (Sharma and Hannafin, 2007). Finally, visual scaffolding design can consider a generic set of guidelines and domainspecific guidelines to provide not only the general structure or process of tasks through their spatial representation but also content-specific aids that consider each context.

Rha and Park (2010) proposed design elements and models of visual scaffolding, especially for web-based problem-solving environments. According to these authors, visual scaffolding in a particular problem-solving case must satisfy the following properties in terms of learning goals, learning processes, learning strategies, and emotional support: 1) regarding learning goals, visual scaffolding should guide the direction or trajectory of problem solving; 2) during the learning process, visual scaffolding should guide the problem-solving process in a visually noticeable manner; 3 ) regarding the learning strategy, visual scaffolding should provide tips or hints in a visually represented manner; and 4) concerning emotional support, visual scaffolding should decrease learners' anxiety, uncertainty, surprise, and disappointment by providing visual cues regarding the following events. These authors further suggested a process for designing visual scaffolding. Additional visual scaffolding design principles and models in technology-based learning environments can be extracted from the design principles and models of both visual information and scaffolding as demonstrated in the previous sections.

Implications can be drawn and synthesized from previous studies concerning information visualization, scaffolding design in web environments, and visual scaffolding design in web-based environments as shown in Figure 2. The visual scaffolding design principles in a web-based learning environment can be categorized into object-related, visual-related, and learner-related principles. Object-related principles involve addressing the target or object of scaffolding. Visual-related principles include principles regarding sense-making, process and structure, articulation, and reflection. In terms of sense-making, visual scaffolding can spatially organize knowledge or information and perform coaching, modelling, and mentoring functions. Concerning process and structure, the required task, activity structure or process can be explicated. For the articulation and reflection, learners' thinking process or understanding can be explicated, and appropriate metacognitive prompts can be provided. The visual-related principles involve the visuals used for the scaffolding. Visual scaffolding can ensure visibility, coupling, and usability. Appropriate visuals include representational, organizational, interpretational, and transformational visuals. When designing visuals, the proximity and simplicity of the display are important, and the spatial organizational function of the visuals is crucial. Finally, the learnerrelated principles guide the designers in considering each learner's differences. The assumptions, cognitive style, needs and experiences of each learner must be taken into account, and the support level and use of each type of visual scaffolding should be manipulated by learners. These variables are elaborated upon in the following section concerning visual scaffolding design principles. 


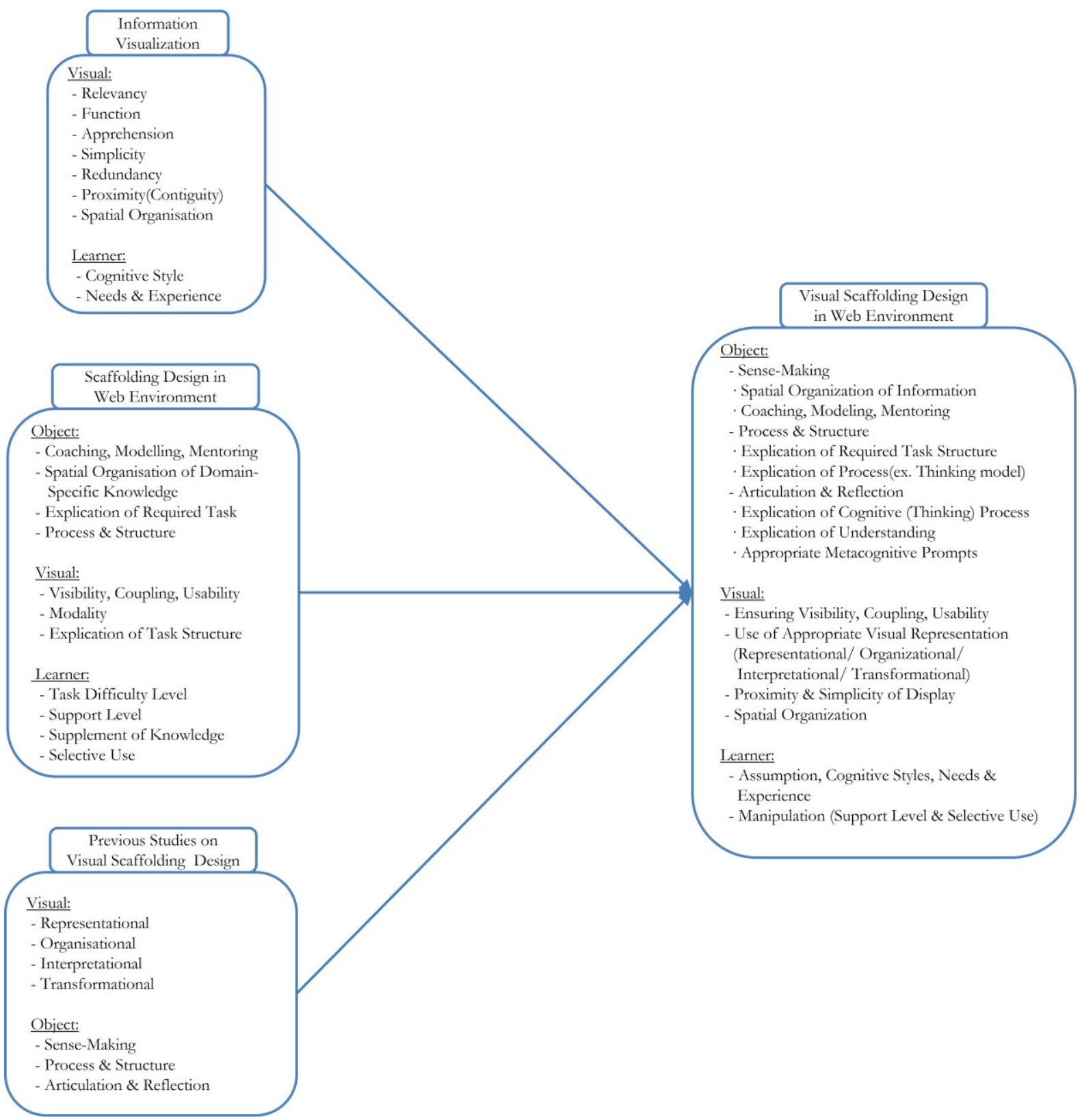

Figure 2: Synthesis of the Literature Review Concerning Visual Scaffolding Design

\section{Visual scaffolding design principles in web-based learning environments}

Based on the implications and variables derived from the literature review, visual scaffolding design principles in a web-based learning environment can be developed as shown in Table 1. 
Table 1: Visual Scaffolding Design Principles in Web-Based Learning Environments

\begin{tabular}{|c|c|c|c|c|}
\hline Category & \multicolumn{2}{|c|}{ Principle } & Guidelines & References \\
\hline \multirow{7}{*}{ Object } & \multirow[b]{2}{*}{$\begin{array}{l}\text { Sense- } \\
\text { Making }\end{array}$} & $\begin{array}{l}\text { 1. Spatial } \\
\text { Organization } \\
\text { of } \\
\text { Information }\end{array}$ & $\begin{array}{l}\text { 1.1. Provide the hierarchical or } \\
\text { structural relationship among the } \\
\text { conceptual components. } \\
\text { 1.2. Provide the big-picture or macro } \\
\text { view of the domain knowledge. }\end{array}$ & $\begin{array}{l}\text { Cheng and Barone (2017), } \\
\text { Hegarty (2011) } \\
\text { Kao, Lehman, and Cennamo } \\
\text { (1997), Kosslyn (2017), } \\
\text { Kinstch \& van Dijk (1978), } \\
\text { Larkin and Simon (1987), } \\
\text { McKenzie (1999), Schwarts } \\
\text { and Heiser (2005), Park } \\
\text { (2019) }\end{array}$ \\
\hline & & $\begin{array}{l}\text { 2. Coaching, } \\
\text { Modelling, } \\
\text { and } \\
\text { Mentoring }\end{array}$ & $\begin{array}{l}\text { 2.1. Visualize worthwhile or additional } \\
\text { information that can guide learners to } \\
\text { carry out tasks towards the goal. } \\
\text { 2.2. Visualize models or examples that } \\
\text { the learners can follow. }\end{array}$ & $\begin{array}{l}\text { Hannafin et al. (2001), } \\
\text { Hannafin, Land, and Oliver } \\
\text { (1999), } \\
\text { Park (2017), Rha and Park } \\
\text { (2010) } \\
\text { Schutt (2003), Sharma and } \\
\text { Hannafin (2007) }\end{array}$ \\
\hline & \multirow[b]{2}{*}{$\begin{array}{l}\text { Process and } \\
\text { Structure }\end{array}$} & $\begin{array}{l}\text { 3. Explication } \\
\text { of the Task } \\
\text { Structure }\end{array}$ & $\begin{array}{l}\text { 3.1. Provide the visual structure of the } \\
\text { set of activities or task. } \\
\text { 3.2. Integrate positional information to } \\
\text { inform the learners of their position in } \\
\text { the macro-structure. }\end{array}$ & $\begin{array}{l}\text { Hannafin, Land, and Oliver } \\
\text { (1999), } \\
\text { Muller (1986), Park (2016), } \\
\text { Quintana et al. (2004), } \\
\text { Sharma and Hannafin (2007) }\end{array}$ \\
\hline & & $\begin{array}{l}\text { 4. Explication } \\
\text { of the } \\
\text { Process }\end{array}$ & $\begin{array}{l}\text { 4.1. Visualize the process of the set of } \\
\text { activities or task. } \\
\text { 4.2. Integrate positional information to } \\
\text { inform the learners their location in the } \\
\text { process. }\end{array}$ & $\begin{array}{l}\text { Hannafin et al. (2001), } \\
\text { Hannafin, Land, and Oliver } \\
\text { (1999), Hegarty (2011) } \\
\text { Kosslyn (2017), Quintana, et } \\
\text { al., (2004), Rubman and } \\
\text { Waters (2000), } \\
\text { Sharma and Hannafin (2007) }\end{array}$ \\
\hline & \multirow{3}{*}{$\begin{array}{l}\text { Reflection } \\
\text { and } \\
\text { Articulation }\end{array}$} & $\begin{array}{l}\text { 5. Explication } \\
\text { of the } \\
\text { Cognitive } \\
\text { Process }\end{array}$ & $\begin{array}{l}\text { 5.1. Provide visual tools that allow the } \\
\text { learners to explicate their ongoing } \\
\text { cognitive process. } \\
\text { 5.2. Provide appropriate visuals that } \\
\text { can suggest a timely cognitive strategy. }\end{array}$ & $\begin{array}{l}\text { Hannafin, et al. (2001), } \\
\text { Hannafin, Land, and Oliver } \\
\text { (1999), Quintana, et al. } \\
\text { (2004), Sharma and Hannafin } \\
\text { (2007), Schutt (2003) }\end{array}$ \\
\hline & & $\begin{array}{l}\text { 6. Explication } \\
\text { of } \\
\text { Understandin } \\
\text { g }\end{array}$ & $\begin{array}{l}\text { 6.1. Provide visual tools that allow the } \\
\text { learners to explicate their } \\
\text { understanding. } \\
\text { 6.2. Provide appropriate visuals that } \\
\text { can enhance the learners' ongoing } \\
\text { understanding. }\end{array}$ & $\begin{array}{l}\text { Coombs (2006), Quintana, et } \\
\text { al. (2004), Rha and Park } \\
\text { (2010), Sharma and Hannafin } \\
\text { (2007), Schutt (2003) }\end{array}$ \\
\hline & & $\begin{array}{l}7 . \\
\text { Metacognitiv } \\
\text { e Prompts }\end{array}$ & $\begin{array}{l}\text { 7.1. Provide timely visual prompts that } \\
\text { can encourage the learners to reflect } \\
\text { on and articulate their thoughts. } \\
\text { 7.2. Provide timely visual prompts that } \\
\text { can suggest appropriate reflection and } \\
\text { articulation strategies. }\end{array}$ & $\begin{array}{l}\text { Hannafin, et al. (2001), } \\
\text { Hannafin, Land, and Oliver } \\
\text { (1999), Quintana, et al. } \\
\text { (2004), Rha and Park (2010), } \\
\text { Sharma and Hannafin (2007) }\end{array}$ \\
\hline \multirow[t]{2}{*}{ Visual } & \multicolumn{2}{|c|}{$\begin{array}{l}\text { 8. Ensuring Visibility, Coupling, } \\
\text { and Usability }\end{array}$} & $\begin{array}{l}\text { 8.1. Ensure that the visual scaffoldings } \\
\text { are initially visible. } \\
\text { 8.2. Provide appropriate visual } \\
\text { scaffolding that matches the content } \\
\text { and other modalities. } \\
\text { 8.3. Provide visual scaffolding that can } \\
\text { be easily and conveniently used by the } \\
\text { learners. }\end{array}$ & $\begin{array}{l}\text { Hannafin, et al. (2001), } \\
\text { Hannafin, Land, and Oliver } \\
\text { (1999), Hegarty (2011) } \\
\text { Kosslyn (2017), Mayer (2001) } \\
\text { Oh (2007), Park (2019), } \\
\text { Quintana, et al. (2002), } \\
\text { Sharma and Hannafin (2007), } \\
\text { Tversky (2002) }\end{array}$ \\
\hline & \multicolumn{2}{|c|}{ 9. Use of Appropriate Visuals } & $\begin{array}{l}\text { 9.1. Use optimal visuals among } \\
\text { representational, organizational, } \\
\text { interpretational, and transformational } \\
\text { visuals that can work most efficiently. }\end{array}$ & $\begin{array}{l}\text { Carney and Levin (1998, } \\
\text { 2002), Carney, Levin, and } \\
\text { Levin (1993), Davis and Linn } \\
\text { (2000), Higbee (1988) }\end{array}$ \\
\hline
\end{tabular}




\begin{tabular}{|c|c|c|c|}
\hline Category & Principle & Guidelines & References \\
\hline & & $\begin{array}{l}\text { 9.2. Title and the grouping of texts are } \\
\text { necessary for the visibility and } \\
\text { conspicuity. }\end{array}$ & $\begin{array}{l}\text { Levin (1980), Mayer (2001) } \\
\text { Park (2019), Rha and Park } \\
\text { (2010), Kim (2006) }\end{array}$ \\
\hline & $\begin{array}{l}\text { 10. Proximity and Simplicity of } \\
\text { the Display }\end{array}$ & $\begin{array}{l}\text { 10.1. Contiguously provide the visual } \\
\text { scaffolding to its object. } \\
\text { 10.2. Simplify the visuals and omit } \\
\text { unnecessary details. }\end{array}$ & $\begin{array}{l}\text { Bentrancourt and Bisseret } \\
\text { (1998), Hegarty (2011) } \\
\text { Kosslyn (2017), Mayer } \\
\text { (2001), Park (2019) }\end{array}$ \\
\hline & $\begin{array}{l}\text { 11. Spatial Organization of the } \\
\text { Toolset }\end{array}$ & $\begin{array}{l}\text { 11.1. Arrange the necessary visual } \\
\text { toolset based on gestalt theory. } \\
\text { 11.2. Arrange the necessary visual } \\
\text { toolsets initially shown at one time. }\end{array}$ & $\begin{array}{l}\text { Cheng and Barone (2017), } \\
\text { Hannafin, et al. (2001), } \\
\text { Hannafin, Land, and Oliver } \\
\text { (1999), Hegarty (2011), } \\
\text { Kosslyn (2017), Quintana et } \\
\text { al. (2004) }\end{array}$ \\
\hline \multirow[t]{2}{*}{ Learner } & $\begin{array}{l}\text { 12. Consideration of Different } \\
\text { Learners }\end{array}$ & $\begin{array}{l}\text { 12.1. Visual scaffolding should be based } \\
\text { on the assumptions or mental models } \\
\text { of the learners. } \\
\text { 12.2. Differentiate the visuals according } \\
\text { to the learners' cognitive style, needs } \\
\text { and preferences. }\end{array}$ & $\begin{array}{l}\text { Braden (1994), Han (2006), } \\
\text { Jonassen (1999), } \\
\text { Oh (2007), Park (2017), } \\
\text { Sharma and Hannafin (2007), } \\
\text { Wileman (1993) }\end{array}$ \\
\hline & $\begin{array}{l}\text { 13. Manipulation of Support } \\
\text { and Use }\end{array}$ & $\begin{array}{l}\text { 13.1. Differentiate the support level } \\
\text { according to the learners' competency. } \\
\text { 13.2. Design visual scaffolding that } \\
\text { learners can selectively use. }\end{array}$ & $\begin{array}{l}\text { Chi, et al. (2001), Jonassen } \\
\text { (1999), Kao, Lehman, and } \\
\text { Cennamo (1997), Park } \\
\text { (2016), Schutt (2003) }\end{array}$ \\
\hline
\end{tabular}

1. Spatial organization of information: To encourage learners to understand domain-specific knowledge more efficiently and effectively, it is necessary to provide the big-picture or macro view of the domain knowledge and the hierarchical or structural relationship among the conceptual components (Kao, Lehman, and Cennamo, 1997; Cheng and Barone, 2017; Hegarty, 2011; Kosslyn, 2017; Larkin and Simon, 1987; McKenzie, 1999). Such a visual structure of information can encourage learners to grasp the overall information easily with a lower cognitive load (Kinstch and van Dijk, 1978; Park, 2019; Schwarts and Heiser, 2005). As displayed in Figure 3, the domain knowledge can be visualized using a visual analogy or visual metaphor (e. g. Greek temple, slide), or be organized hierarchically reflecting the characteristics of the contents. 

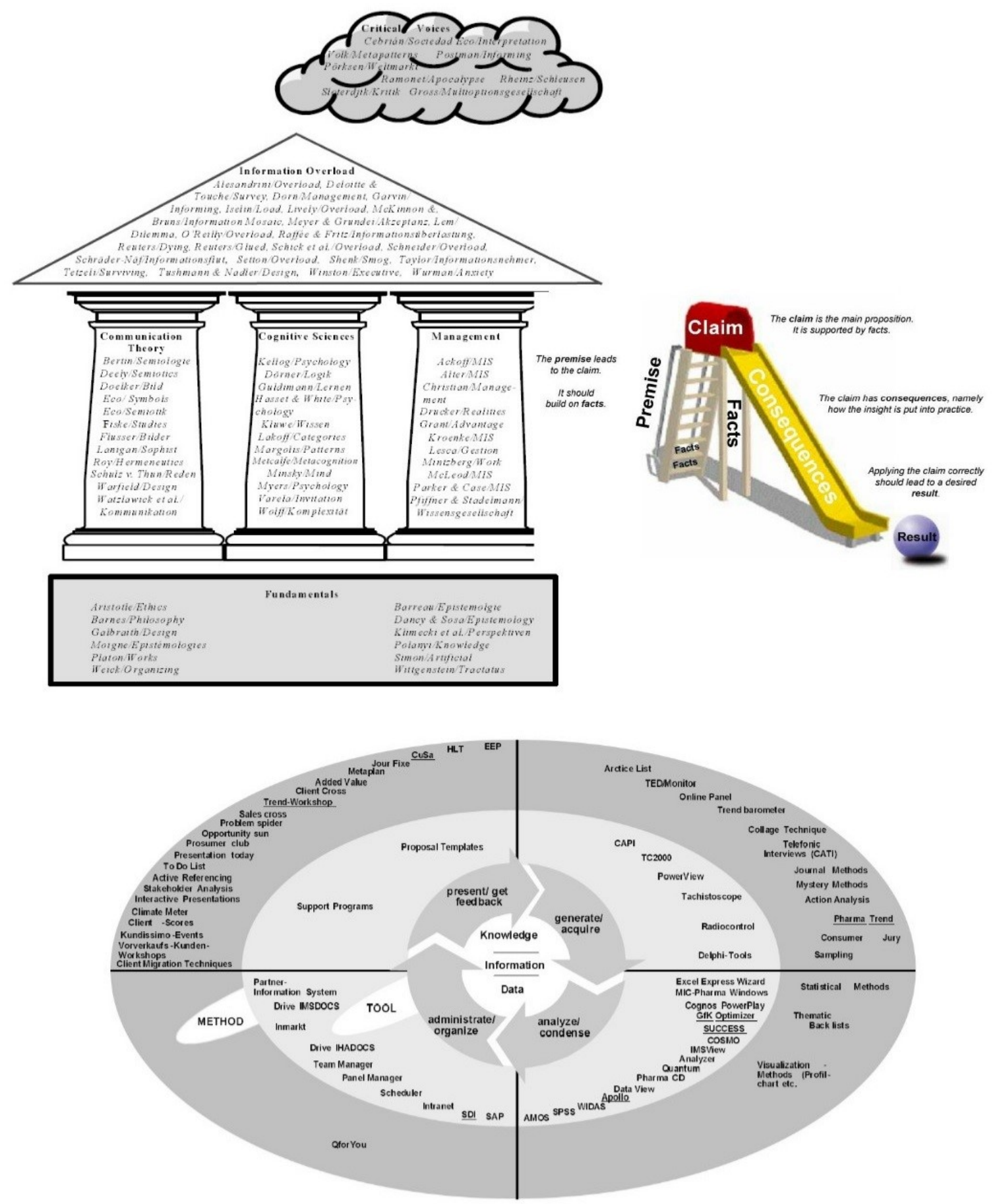

Figure 3: Spatial Organization of Information (Reproduced with permission from Eppler, 2003)

2. Coaching, modelling, and mentoring: Visual scaffolding may coach learners to become excellent problem solvers by facilitating learners' schema building. Visual scaffolding can guide learners through the desired activities and procedures and provide appropriate mentoring (Hannafin, et al., 2001; Hannafin, Land, and Oliver, 1999; Schutt, 2003; Sharma and Hannafin, 2007). Information necessary for solving the problem, models or examples that learners can follow can be provided as visual scaffolding (Rha and Park, 2010; Park 2017, 2019). In Figure 4, visual scaffolding can guide learners' problem solving process step by step by visualizing each step;1) understanding the problem situation, 2) identifying possible solutions, 3) analyzing pros and cons of solutions in individual and social aspects, 4) decision-making, 5) announcing my decision. 


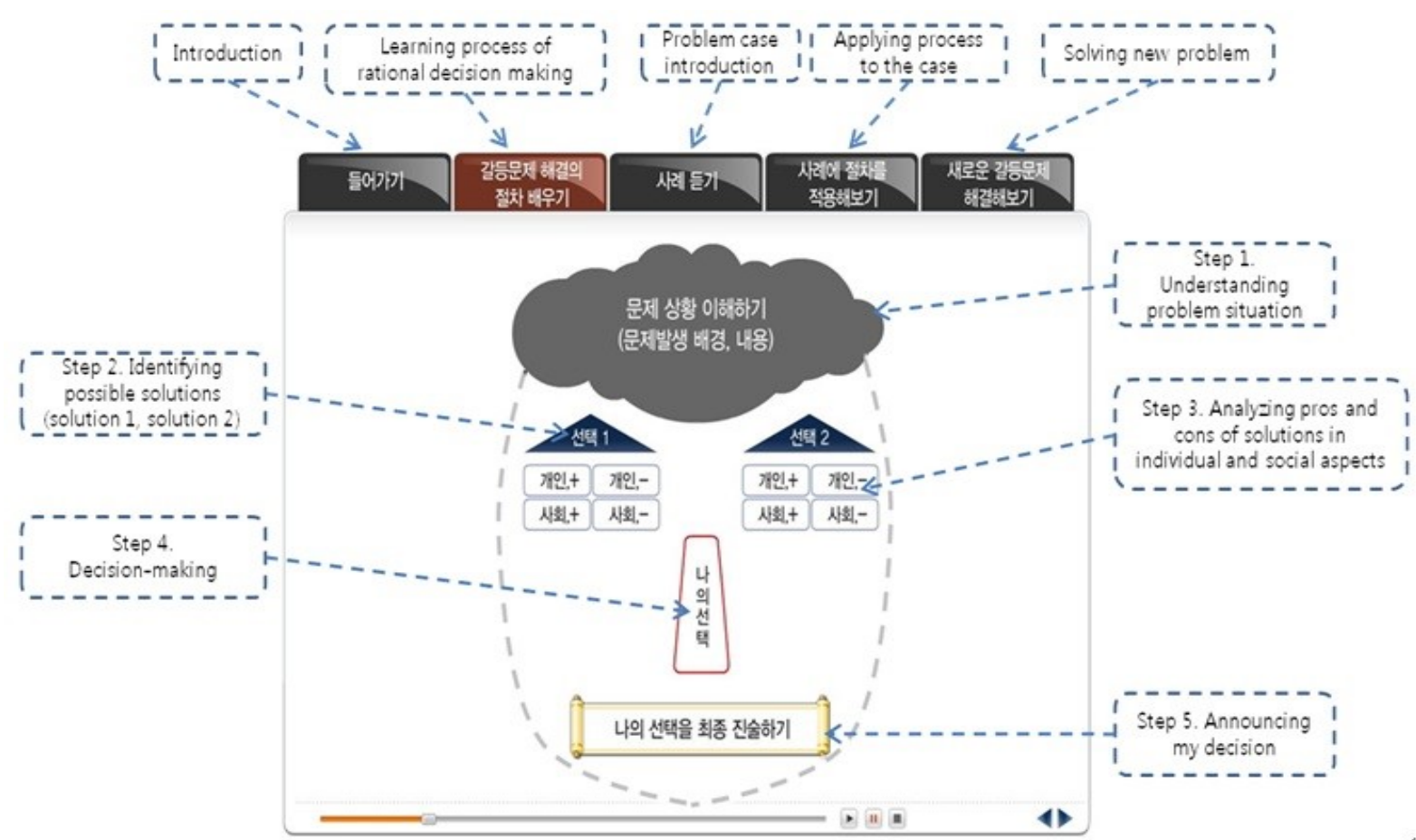

Figure 4: Coaching, Modeling, and Mentoring (with permission from Rha and Park, 2010)

3. Explication of the task structure: This principle suggests that visual scaffolding can visualize not only domainspecific knowledge but also the activity or task structure of the content. The set of activities or tasks can be visually organized (Hannafin, et al., 2001; Hannafin, Land, and Oliver, 1999; Quintana, et al., 2004; Sharma and Hannafin, 2007). Consequently, learners can obtain a macro view with a lower cognitive load and positional information regarding the tasks they are required to perform and their current position relative to the goal (Muller, 1986; Park, 2016). Learners can benefit by being provided the whole structure of the task they need to carry out at one time as a thumbnail (See Figure 5.).
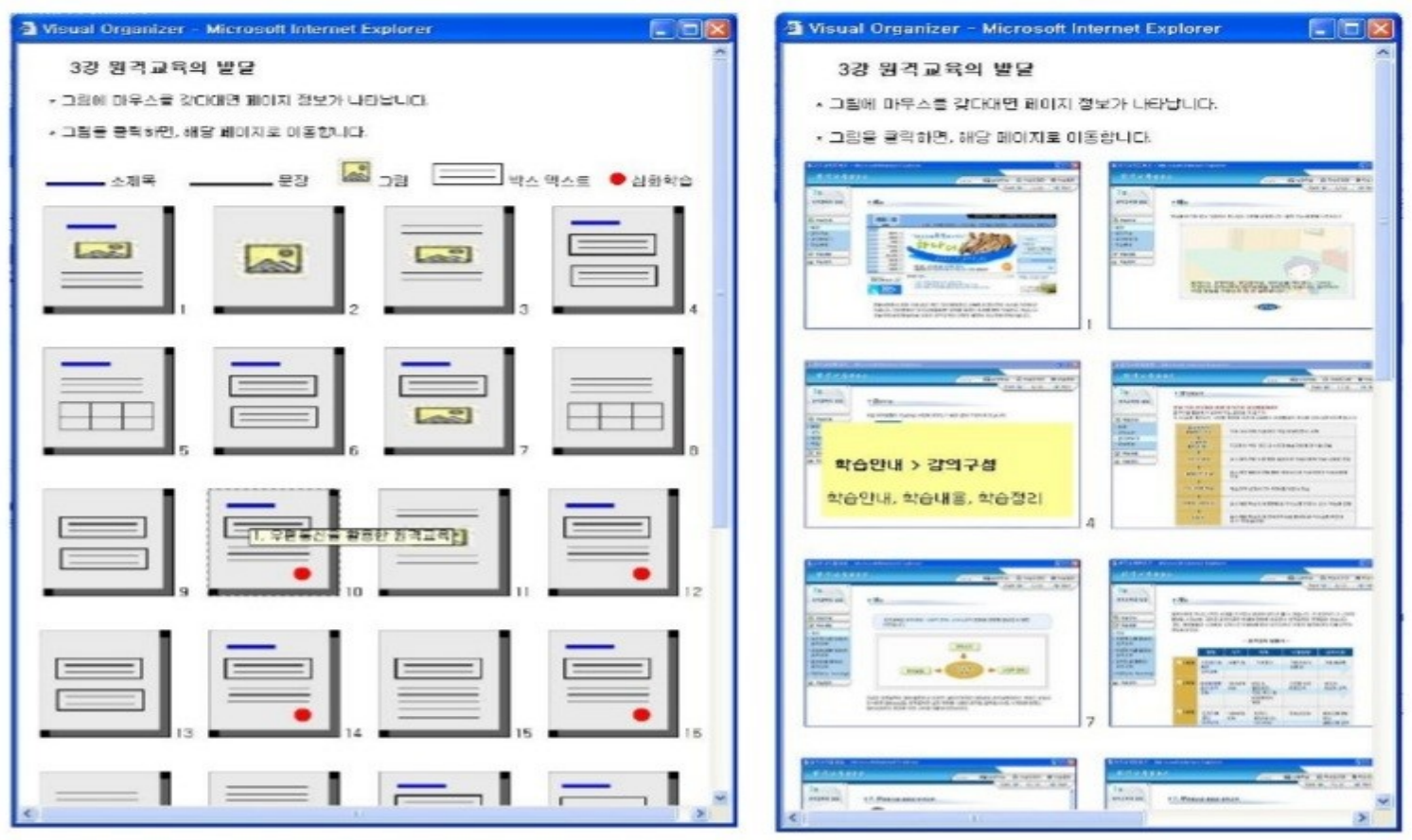

Figure 5: Explication of the whole task structure (Reproduced with permission from Han, 2016) 
4. Explication of the process: The process and structure of the task can be provided visually. This information regarding the activity process and the learners' position can also allow learners to lessen their cognitive load in performing the task and obtain their positional information (Hannafin, et al., 2001; Hannafin, Land, and Oliver, 1999; Muller, 1986; Park, 2016; Quintana, Krajcik, and Soloway, 2002; Sharma and Hannafin, 2007). (See Figure 6)

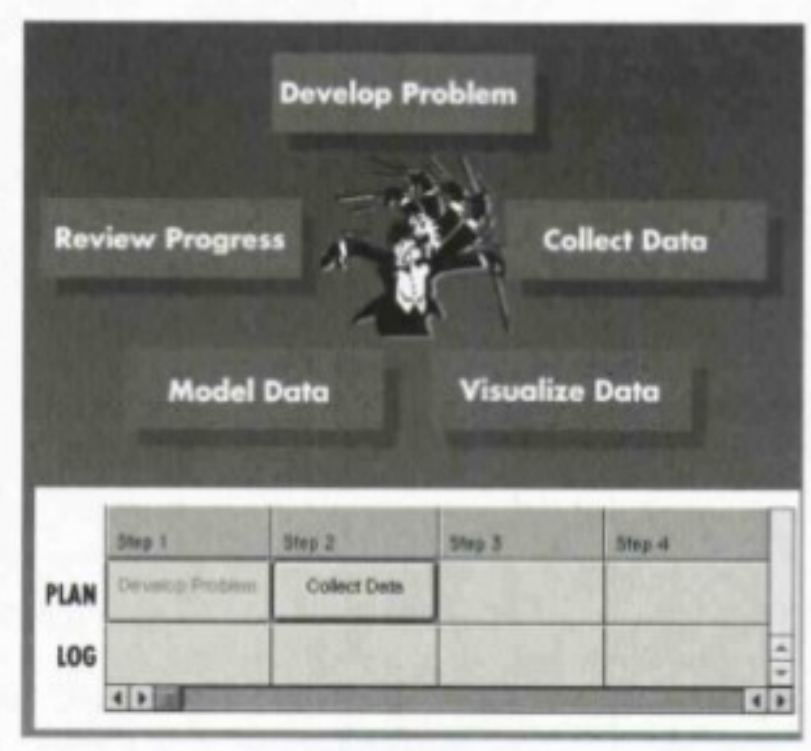

Figure 6: Spatial Organization of Visual (Quintana, Krajcik, and Soloway, 2002)

5. Explication of the cognitive process: A primary consideration when providing visual scaffolding lies in rendering the learners' cognitive processes explicit using appropriate representation (Sharma and Hannafin, 2007). Learners can be provided with procedural visual scaffolding, such as a thinking model, to reduce their extraneous cognitive load. Cognitive strategies that can help learners perform each process are also helpful (Hannafin, et al., 2001; Hannafin, Land, and Oliver, 1999; Schutt 2003; Quintana, Krajcik, and Soloway, 2002). As shown in Figure 7, learners can be supported by the meta-level visual scaffolding which helps their cognitive process to understand the overall activities and how activities are related to each other.

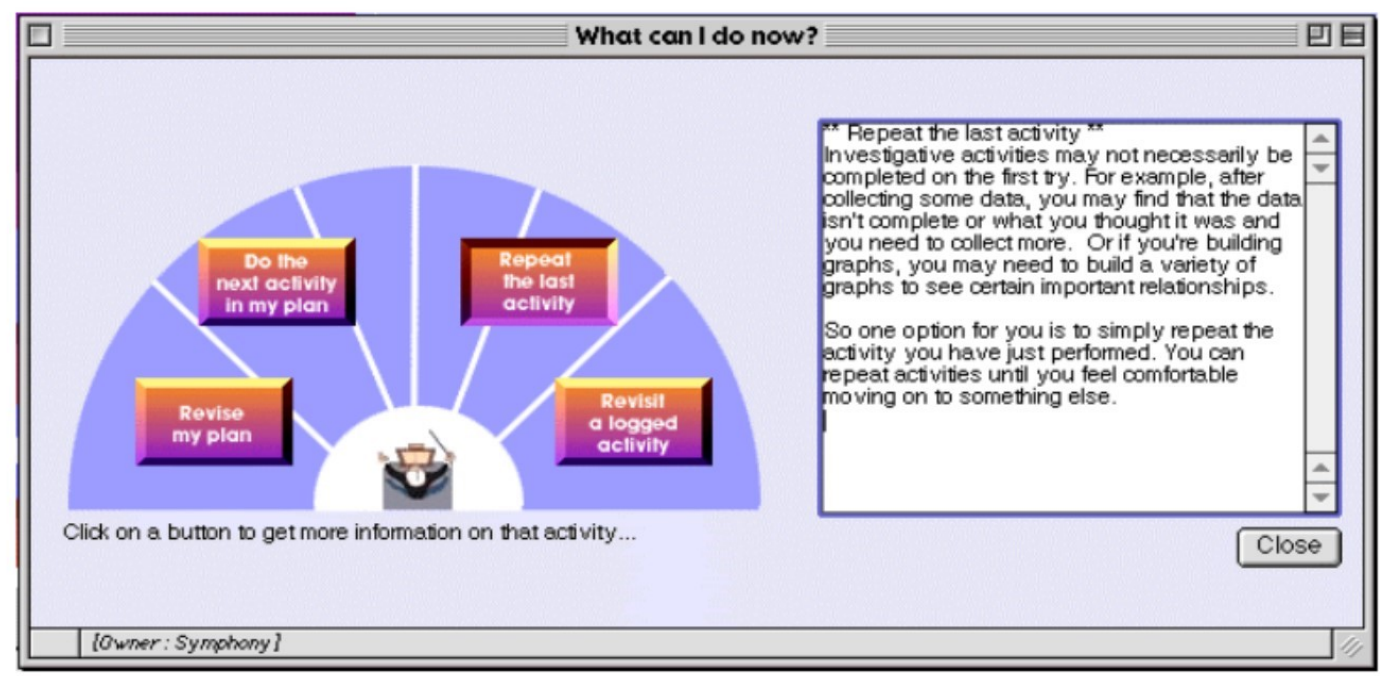

Figure 7: Explication (Reproduced with permission from Quintana, Krajcik, and Soloway, 2002)

6. Explication of understanding: Similarly, it is crucial to provide appropriate visual tools that can explicate learners' understanding and effectively support their ongoing understanding to lessen the cognitive load and encourage the learners to focus on the important features (Coombs, 2006; Hannafin, et al., 2001; Hannafin, 
Land, and Oliver, 1999; Sharma and Hannafin, 2007). For example, the schemata scaffolding suggested by Coombs (2006) supports learners in clarifying their understanding and provides procedural and strategic help (See Figure 8). What does PE mean in this visual?

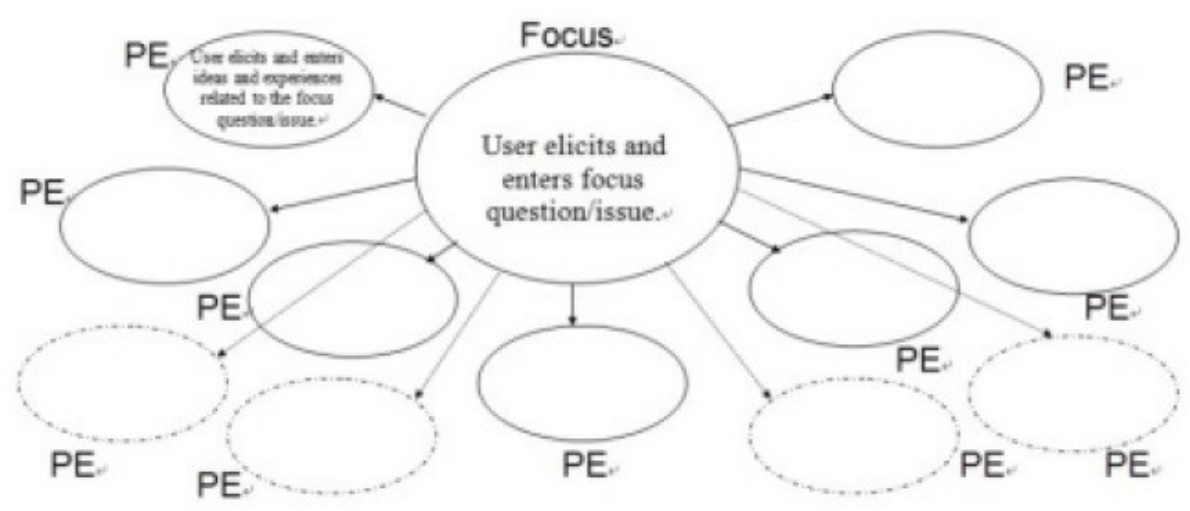

Figure 8: Explication of Understanding (Reproduced with permission from Coombs, 2006)

7. Metacognitive prompts: Visual scaffolding can function as a strategic metacognitive aid in articulation and reflection (Hannafin, Land, and Oliver, 1999; Hannafin, et al., 2001; Quintana, et al., 2004). Specifically, metacognitive prompts can remind learners to reflect on goals or relate the specific resource or outcome to the problem or task using appropriate representations such as speech bubbles shown in Figure 9. Such prompts contribute to encouraging learners to reflect on and articulate their thoughts and strategies (Rha and Park, 2010; Sharma and Hannafin, 2007).

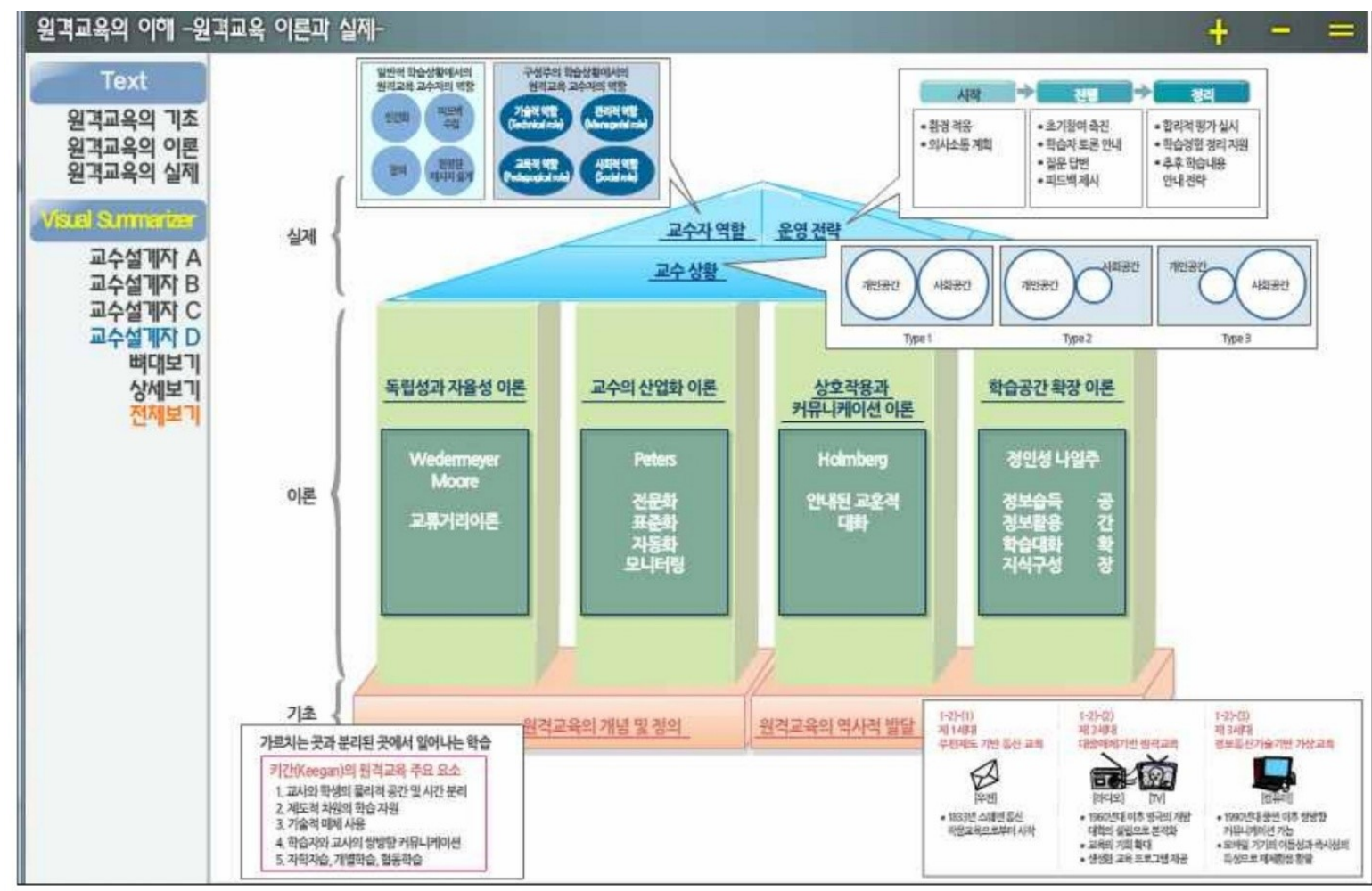

Figure 9: Metacognitive Prompts (Reproduced with permission from Lee, 2012)

8. Ensuring visibility, coupling, and usability: Visuals used for scaffolding need to be easy to notice, relevant, and convenient to use. Visual scaffolding should be initially visible rather than appearing gradually to minimize learners' cognitive load and unnecessary effort to find necessary support (Hannafin, et al., 2001; Hannafin, Land, and Oliver, 1999; Sharma and Hannafin, 2007; Park, 2019). Furthermore, visual scaffolding should be designed to be relevant to the content and other modalities to function as intended (Hegarty, 2011; Kosslyn, 
2017; Mayer, 2001; Tversky, 2002; Oh, 2007; Park, 2019). It is also important that the provided visual scaffolding is easy to use (Hannafin, et al., 2001; Hannafin, Land, and Oliver, 1999; Sharma and Hannafin, 2007). (See Figure 10.)
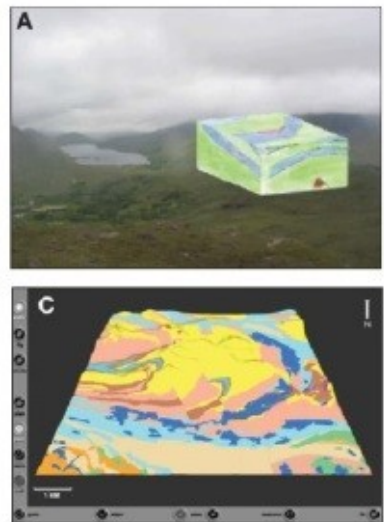

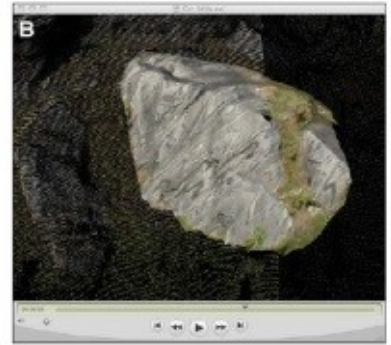

$\cdots+\cdots$

Figure 10: Visibility, Coupling, Usability (Reproduced with permission from Whitmeyer et al., 2012)

9. Use of appropriate visuals: When visual scaffolding is designed, its optimal function among representational, organizational, interpretational, and transformational visuals should be considered (Carney and Levin, 1998; 2002; Carney, Levin, and Levin, 1993; Davis and Linn, 2000; Higbee, 1988; Levin, 1980; Mayer, 2001; Rha and Park, 2010; Park, 2019). Representational visuals depict or mirror a part or all of the content or task for elaboration. Organizational visuals provide a structure or process to the content (See Figure 11). Interpretational visuals facilitate learning through explanation or analogy, and transformational visuals work as mnemonics to associate the visuals with the content. not needed When displaying textual information, grouping relevant text leaving the whitespace and inserting titles and subtitles are recommended in order to promote the readability and visibility of the visual information (Kim, 2006; Park, 2019).
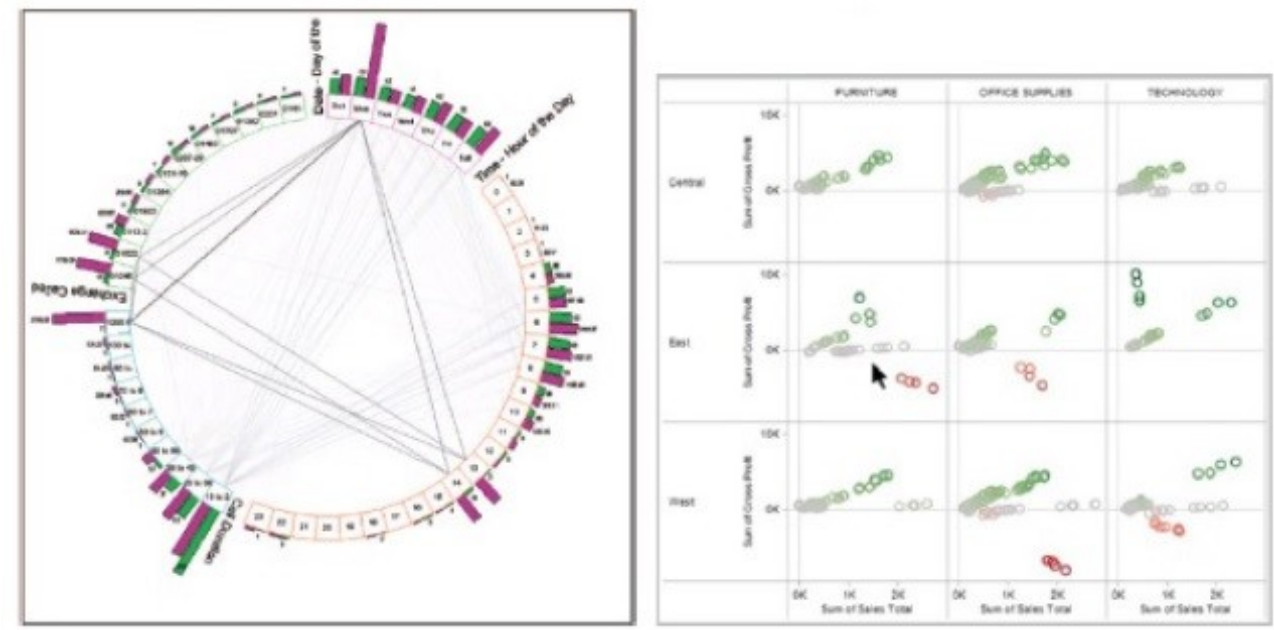

Figure 11: Use of Appropriate Visuals (Reproduced with permission from Urlich, 2012)

10. Proximity and simplicity of the display: The principle of the proximity and simplicity of the display suggests that provided visuals should be contiguous to their object and simplified to provide information most efficiently and effectively. As shown in Figure 12, visual needs to be proximal to its object or textual information to decrease the split attention effect (Hegarty, 2011; Kosslyn, 2017; Mayer, 2001; Park, 2019) and allow learners to easily find the necessary information. Furthermore, the visuals should consist of essentials and omit less important details to encourage learners to focus on the key aspects of the content (Bentrancourt and Bisseret, 1998; Mayer, 2001; Park, 2019). 


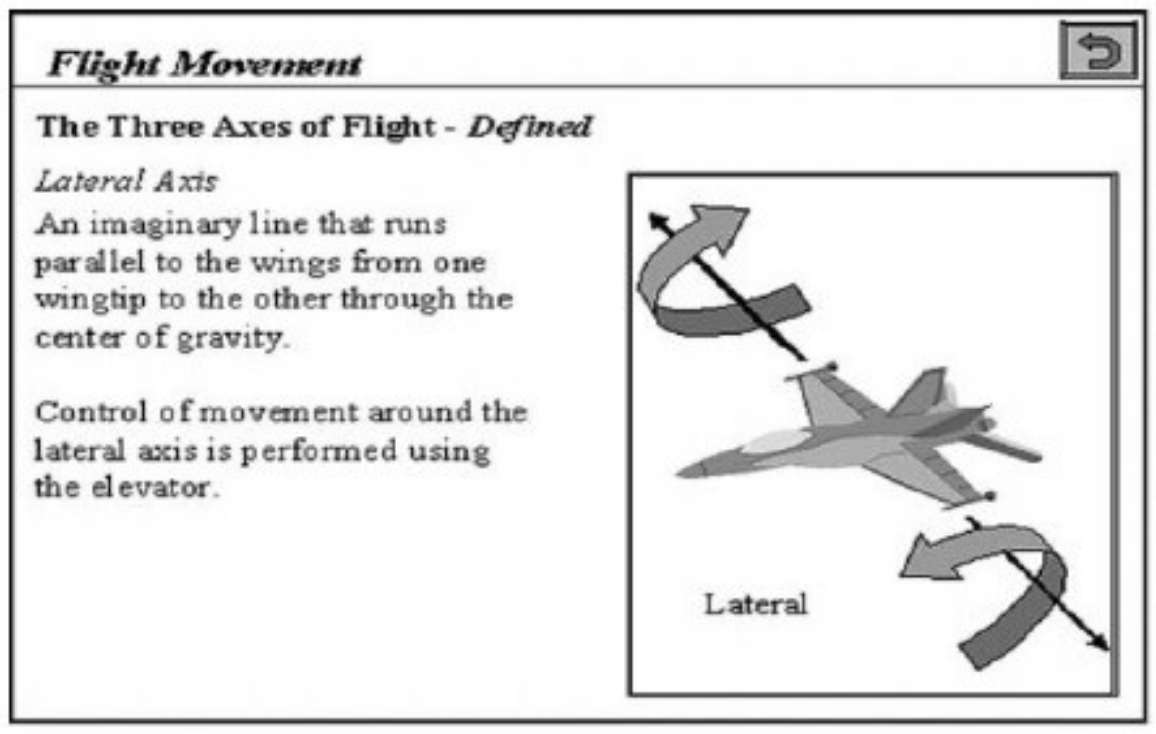

Figure 12: Proximity and Simplicity (Reproduced with permission from Cuevas, Fiore, and Oser,, 2002)

11. Spatial organization of the toolset: Regarding the arrangement of the visual toolsets that learners can utilize, the tools and artefacts should be organized based on gestalt theory around the semantics of the discipline (Cheng and Barone, 2017; Hannafin, et al., 2001; Hannafin, Land, and Oliver, 1999; Hegarty, 2011; Kosslyn, 2017; Quintana, et al., 2004). Thus, the interface needs to be spatially organized in a visually efficient and effective way such that learners can naturally and conveniently find and use what they need within a toolset (See Figure 13).

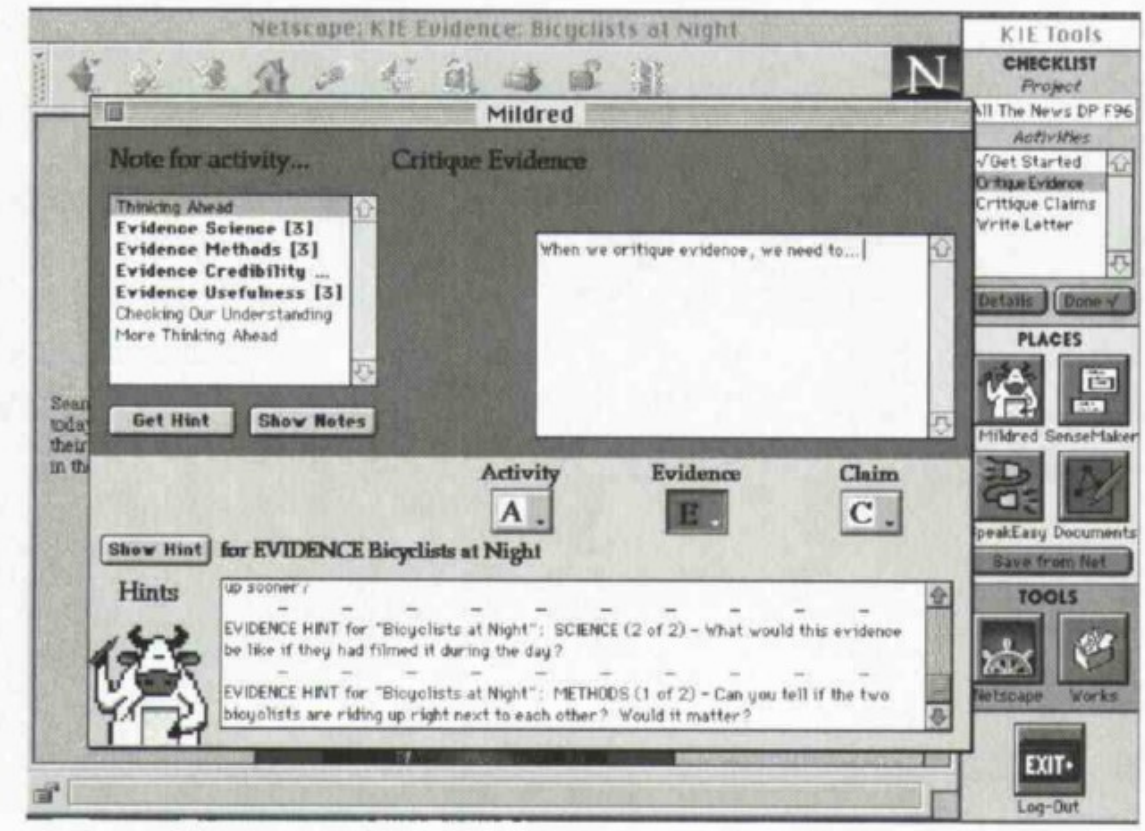

Figure 13: Spatial Organization of the Toolset (Reproduced with permission from Quintana, et al., 2004)

12. Consideration of different learners: The design of visual scaffolding needs to consider the variety and differences among learners (Jonassen, 1999; Oh, 2007; Sharma and Hannafin, 2007). It is important to consider learners' mental models and their assumptions regarding specific visuals when designing visuals. Furthermore, it is necessary to differentiate visuals by considering learners' various cognitive styles, needs, and preferences. For example, visual learners can choose more visually-dominated scaffolding, whereas verbal learners can choose more verbally-dominated scaffolding among the various types of visual scaffoldings (Braden, 1994; Han, 2006; Park, 2017). Some learners may need and prefer more abstract visuals without words, while other 
learners need and prefer more concrete visuals with words as shown in Figure 14 (Han, 2006; Park, 2017; Wileman, 1993).
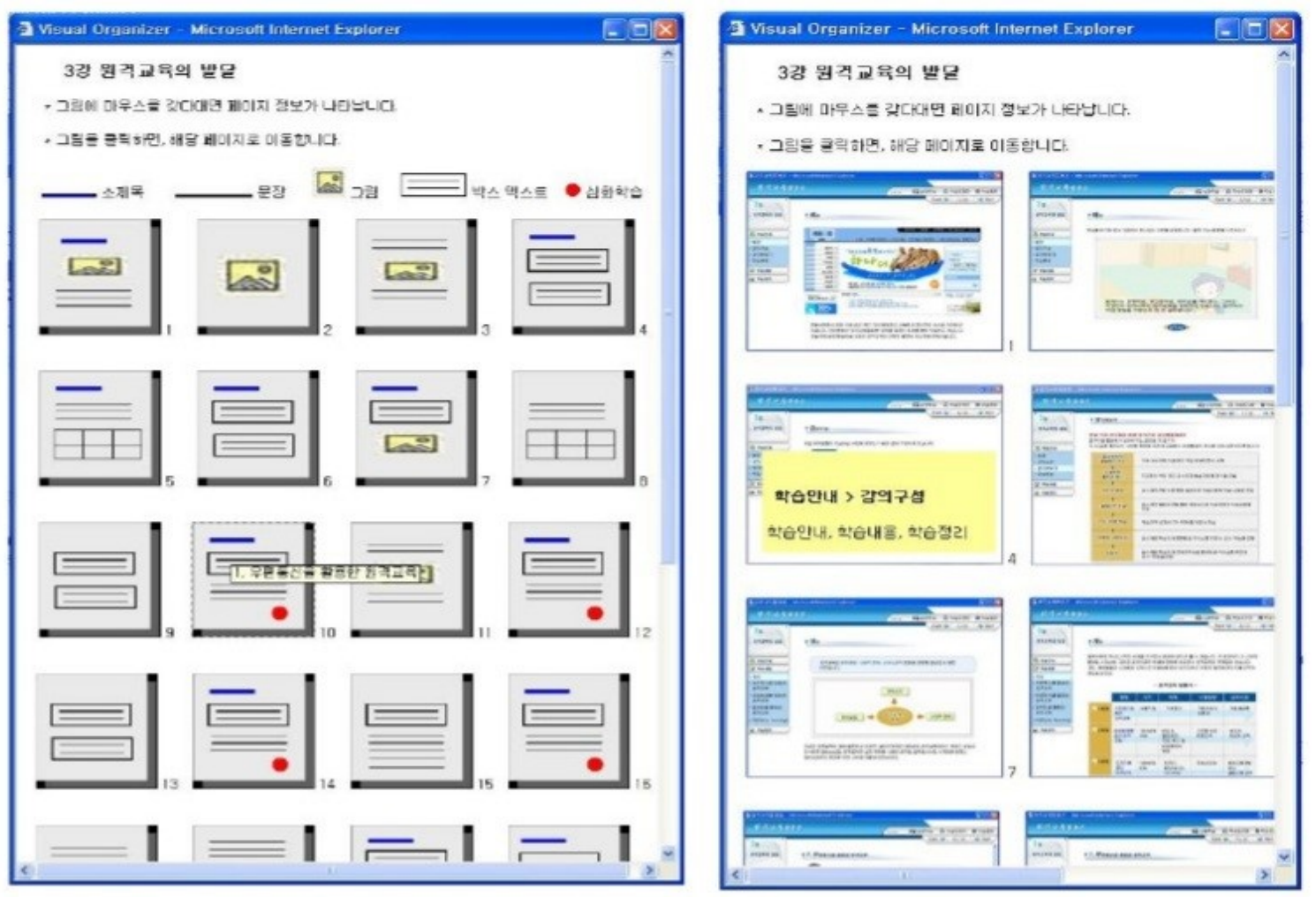

Figure 14: Consideration of Different Learners (Reproduced with permission from Han, 2006)

13. Manipulation of support and use: In accordance with learners' differences, the manipulation of facilitation and use should differ. The more competent the learner, the lower the level of support needed, whereas the less competent the learner, the greater the amount of support needed (Kao, Lehman, and Cennamo, 1997; Jonassen, 1999; Schutt, 2003). Furthermore, visual scaffolding should be designed such that learners can select the necessary level of support to maximize the individual impact of visual scaffolding (Chi, et al., 2001; Schmidt, et al., 2007; Schutt, 2003). (See Figure 15)
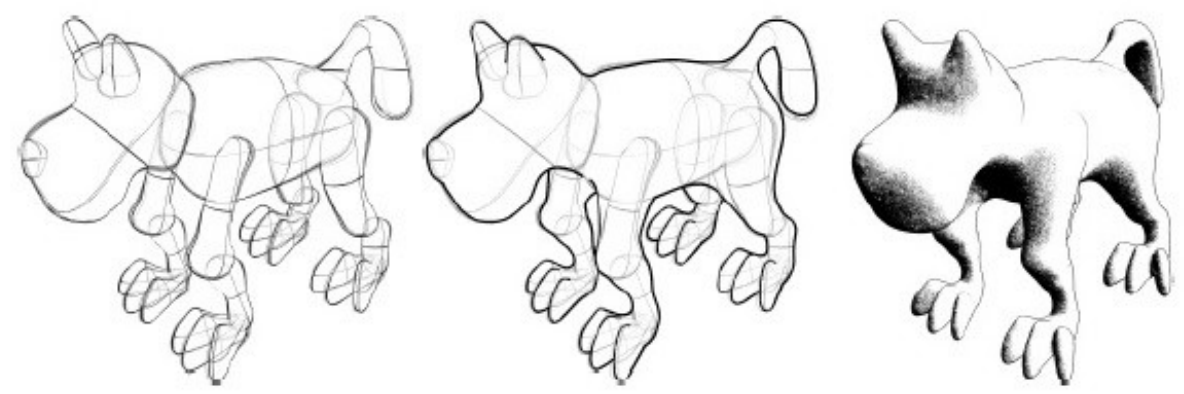

Figure 15: Manipulation of Support and Use (Reproduced with permission from Schmidt, et al., 2007)

\section{Discussion and Conclusion}

These design principles and guidelines can effectively support learners in terms of sense-making, procedural and structural understanding, and the reflection and articulation process by using optimal visuals and considering learners' different needs, experiences, and appropriate levels of help. The specific visual scaffolding design principles include 1) the spatial organization of information, 2) coaching, modelling, and 
mentoring, 3) explication of the task structure, 4) explication of the process, 5) explication of the cognitive process, 6) explication of understanding, 7) metacognitive prompts, 8) ensuring visibility, coupling, and usability, 9) the use of appropriate visuals, 10) proximity and simplicity of the display, 11) spatial organization of the toolset, 12) consideration of different learners, and 13) manipulation of support and use.

Visual scaffolding is expected to allow learners to understand the content knowledge more efficiently and effectively by providing visual representation, encourage learners to understand the process and the structure of their learning, and catalyse learners' metacognition. These functions of visual scaffolding are deeply related to the potentials of visuals which can naturally provide richer information by spatially scattering pieces of information on a screen in web environment (Rha and Park, 2010). The spatially organized and provided visuals possess not only the structural and metacognitive information but also tacit and supplementary information which can further facilitate learning. For example, in Quintana, Krajcik, and Soloway's (2002) research on visual scaffolding in science inquiry learning, the instructors have not numbered the order of the process but just arranged the step in a circle shape, so that the learner can instinctively understand the clockwise process of their inquiry, starting from the top, without additional guidance (See Figure 6).

In terms of the use of visuals, visual scaffolding can be more helpful when it is clear and simple, and located in relevant positions coupling well with other information. When a detailed picture is needed, representational visuals can be used, but normally, too many details may hinder learning by causing cognitive overload. Organizational and interpretational visuals can be in the simplest form in order to direct learners' attention and deliver important information efficiently and effectively.

not needed visual scaffolding should be designed in a way that the visual matches well with learners' assumption or mental model, cognitive style or preferences $\leftarrow$ wordy and visual scaffolding should be easy for learners to understand and manipulate. Without considering learners, the visual scaffolding may be misleading or less helpful.

Likewise, by optimally using those aspects of visual scaffolding, learners can be provided a meta-cognitive and macro information of the task process itself as well as richer and more structural information regarding the domain-specific knowledge. Such abundant information gathered from visual scaffolding is expected to lead to learners' higher-ordering thinking and obtaining more integrative knowledge.

This paper has limitations in the following aspects. First, the principles and guidelines proposed in this research require rigorous internal and external validation to provide more solid prescriptions for visual scaffolding design. This paper lacks a case study or other types of field tests which can practically measure the effectiveness of visual scaffolding principles proposed. Second, although this research aimed to provide general principles for visual scaffolding design in a web environment, these principles might not be sufficient and detailed for each specific learning context, including different content types, learner levels, and learning environments. Third, this research does not systematically address visual scaffolding design process, although the process of a visual scaffolding design model could be remarkably helpful for visual scaffolding design in practice. Last but not least, the principles extracted are not applicable for visually-impaired learners as the principles basically assume that the learners are able to see the visual scaffolding provided. However, more universal design principles which are able to be accessed by disabled learners who have difficulty seeing, are hard of hearing, and so on, are more desirable.

The directions for future research are numerous and include the testing of the internal and external effectiveness of visual scaffolding design principles in different contexts with different types of learning, developing more context-specific visual scaffolding design principles, developing a procedural visual scaffolding design model, and establishing more universal design principles of different types of scaffolding such as audio-based one which can be used by people with visual impairment.

\section{References}

Alibali, M., 2006. Does visual scaffold facilitate students' mathematics learning? Evidence from early algebra. Available at: from http://ies.ed.gov/funding/grantsearch/details.asp?ID=54 [Accessed September 12, 2008]

Alibala, M., and Nathan, M. J,. 2007. Teachers' gestures as a means of scaffolding students' understanding: Evidence from an early algebra lesson. In R. Pea, B. Barron, and S. J. Derry, eds. Video Research in the Learning Sciences. Mahwah, NJ: Erlbaum. 
Bentrancourt, M., and Bisseret, A., 1998. Integrating textual and pictorial information via popup windows: An experimental study. Behavior and Information Technology. 17 (5), pp.263-273.

Bull, K. S., Shuler, P., Overton, R., Kimball, S., Boykin, C., and John, G., 1999. Processes for developing scaffolding in a computer mediated learning environment. Paper presented at the American Council of Rural Special Education(ACRES) conference, Albuquerque, New Mexico. March 25-27.

Carney, R. N., Levin, M. E., and Levin, J. R., 1993. Mnemonic strategies: Instructional techniques worth remembering. Teaching Except. Child.25 (4), pp.24-30.

Carney, R.N., and Levin, J. R., 1998. Coming to terms with the keyword method in introductory psychology: A "neuromnemonic" example. Teaching Psychology, 25 (2), pp.132-134.

Carney, R. N., and Levin, J. R., 2002. Pictorial illustrations still improve students' learning from text. Educational Psychology Review, 14 (1), pp.5-26.

Carrier, K. A., and Tatum, A. W., 2006. Creating sentence walls to help English language learners develop content literacy. The Reading Teacher, 60 (3), pp.285-288.

Cheng, P. C., and Barone, R., 2017. Representing complex problems: A representational epistemic approach. In D. H. Jonassen, eds. Learning to solve complex scientific problems (pp. 97-130). New York: Lawrence Erlbaum.

Chi, M. T. H., Siler, S. A., Jeong, H., Yamauchi, T., and Hausmann, R. G. M., 2001. Learning from human tutoring. Cognitive Science, 25 (4), pp.471-533.

Coombs, S., 2006. Engaging Learners through Critical Thinking Scaffolds. The MirandaNet Braided Learning e-Journal, MirandaNet Fellowship. Available at: http://www.mirandanet.ac.uk/cgibin/journals/search_ej.pl?runtype=news;ejtype=ins, 1.11.07. [Accessed DD Month YYYY]

Creswell, J. W., 2009. Research design: Qualitative, quantitative, and mixed methods approaches, 3rd eds. Thousand Oaks, CA: Sage.

Creswell, J. W., and Clark, V. L. P., 2017. Designing and conducting mixed methods research. Thousand Oaks: CA: Sage.

Cuevas, H. M., Fiore, S. M., and Oser, R. L., 2002. Scaffolding cognitive and metacognitive processes in low verbal ability learners: Use of diagrams in computer-based training environments. Instructional Science, 30 (6), pp.433-464.

Davis, E. A., and Linn, M. C., 2000. Scaffolding students' knowledge integration: Prompts for reflection in kie. International Journal of Science Education, 22 (8), pp.819-837.

Eppler, M. J. (2003). The image of insight: The use of visual metaphors in communication of knowledge. Paper presented at the Proceedings of I-KNOW.

Gibbons, B., 2008. Elementary preservice teachers' utilization of English language development instructional strategies in the teaching of science to English learners. Multicultural Education,15 (3), pp.50-53.

Guzdial, M., 1994. Software-realized scaffolding to facilitate programming for science learning. Interactive Learning Environment, 4 (1), pp.1-44.

Han, A., 2006. Design and utilization of the visual organizers in web-based learning. Unpublished doctoral dissertation. Seoul National University, Seoul, Korea.

Hannafin, M., Land, S., and Oliver, K., 1999. Open learning environments: foundations, Methods, and Models. In K. Hogan \& M. Pressley, eds. Scaffolding student learning: instructional approaches and issues (pp.115-140). Cambridge, MA: Brooklyne Books.

Hannafin, M. J., McCarthy, J. E., Hannafin, K. M., and Radke, P., 2001. Scaffolding performance in EPSSs: Bridging theory and practice. Proceedings of 2001 ED-MEDEA World Conference on Educational Multimedia, Hypermedia, \& Telecommunications, pp.658-663.

Hart, C., 2001. Doing a literature search: a comprehensive guide for the social sciences. London, UK: Sage Publications, Inc.

Hart, C., 2018. Doing a Literature Review: Releasing the Research Imagination. London: Sage Publications.

Hassett, D. D., and Schieble, M. B., 2007. Finding space and time for the visual in K-12 literacy instruction. The English Journal, 97 (1), pp.62-68.

Hegarty, M., 2011. The cognitive science of visual-spatial displays: Implications for design. Topics in cognitive science, 3 (3), pp.446-474.

Higbee, K. L., 1988. Your Memory: How It Works and How to Improve It 2nd eds. New York, NY: PrenticeHall.

Jonassen, D. H., 1999. Designing constructivist learning environments. In C. M. Reigeluth, eds. Instructional-design theories and models, Vol. 2(pp. 215-239). New Jersey: Lawrence Erlbaum Associates.

Jonassen, D. H., \& Hung, W., 2006. Learning to troubleshooting: A new theory-based design architecture. Educational Psychology Review, 18 (1), pp.77-114.

Kao, M. T., Lehman, J. D., and Cennamo, K. S., 1996. Scaffolding in Hypermedia assisted instruction: An example of integration. Paper presented at the selected research and development presentations at the national convention of the Association for Educational Communications and Technology(AECT), Indianapolis, IN.

Kali, Y., and Linn, M. C., 2008. Designing effective visualizations for elementary school science. The elementary school journal, 109 (2), pp.181-198.

Kidwai, K., Mynuofu, M., Swain, W. J., Ausman, B. D., Lin, H., and Dwyer, F., (2004). Effect of visual scaffold and animation on students performance on measure of higher order learning. Paper presented at the selected research and development presentations at the national convention of the Association for Educational Communications and Technology(AECT), Chicago, IL.

Kim, J. Y., and Lim, K. Y., 2019. Promoting learning in online, ill-structured problem solving: The effects of scaffolding type and metacognition level. Computers \& Education, 138, pp.116-129. 
Kim, S., 2006. A study on the text reduction in e-learning environment. Unpublished doctoral dissertation. Seoul National University. Seoul, Korea.

Kintsch, W., and Van Dijk, T. A., 1978. Toward a model of text comprehension and production. Psychological review, 85 (5), pp.363-395.

Koes, H, S., and Hanum, M. R., 2019. Nurturing higher order thinking ability through visual scaffolding in group investigation. Journal of Physics: Conference Series 1185 (1), pp.1-9.

Kosslyn, S. M., 2017. The science of learning. In S. M. Kosslyn \& B. Nelson, eds. Building the Intentional University: Minerva and the Future of Higher Education (pp. 149-164). Cambridge, Massachusetts: MIT Press.

Larkin, J. H. and Simon, H. A., 1987. Why a Diagram is (Sometimes) Worth Ten Thousand Words. Cognitive Science 11 (1), 65-100. 10.1016/S0364-0213(87)80026-5.

Levin, J. R., 1980. Try a new method of vocabulary instruction. Weekly Reader (Teacher's Edition 4), 61 (25), 1-3.

Levin, J. R., Divine-Hawkins, P., Kerst, S. M., and Guttmann, J., 1974. Individual differences in learning from pictures and words: The development and application of an instrument. Journal of Educational Psychology, 66 (3), pp.296-303.

Lim, C., Song, H.D. and Lee, Y., 2012. Improving the usability of the user interface for a digital textbook platform for elementary-school students. Educational Technology Research and Development, 60 (1), pp.159-173.

Marai, G. E., 2015. Visual scaffolding in integrated spatial and nonspatial analysis. In E. Bertini and J. C. Roberts, eds. In Proceedings of the EuroVis Workshop on Visual Analytics (EuroVA), 13-17.

Patarakin, E., Burov, V., and Remorenko, I., 2017. Scaffolding educational community of practice using visual storytelling. In Proceedings of the 10th International Conference on Theory and Practice of Electronic Governance, pp.355-358.

Mayer, R. E., 2001. Multimedia Learning. New York, NY: Cambridge University Press.

Mayer, R. E., and Anderson, R. B., 1991. Animations need narrations: An experimental test of a dual-coding hypothesis. Journal of Educational Psychology, 83 (4), pp.484.

Mayer, R. E., and Anderson, R. B., 1992. The instructive animation: Helping students build connections between words and pictures in multimedia learning. Journal of Educational Psychology, 84 (4). 444.

Mayer, R. E., Bove, w., Bryman, A., Mars, R., and Tapangco, L., 1996. When less is more: Meaningful Learning from visual and verbal summaries of science textbook lessons. Journal of Educational Psychology, 88, pp.64-73.

McKenzie, J., 2000. Scaffolding for success. Beyond Technology: Research, Questioning and the information literate school community. [Electronicversion]. Retrieved October 29, 2006 from the From Now On (FNO)website: http://fno.org/dec99/scaffold.html.

Norman, D. A., 1986.Cognitive Engineering. In D. A. Norman \& S. W. Draper, eds. User centered system design: New perspectives on human-computer interaction. Hillsdale, NJ: Erlbaum Associates.

Norman, D. A., 1988. The Design of Everyday Things. New York, NY: Basic Books.

Oh, B., 2007. A Study of Information Design Paradigm focused on User Experience. Unpublished doctoral dissertation. Seoul: Seoul National University.

Okebukola, P. A., 1992. Concept mapping with a cooperative learning flavor. The American Biology Teacher, 54 (4), 218221.

Paivio, A., 1971. Imagery and Verbal Processes. New York, NY: Psychology Press.

Paivio, A., 1986. Mental Representations: A dual coding approach. New York, NY: Oxford University Press.

Park, S., 2016. A developmental study on a SPAT design model for mobile learning. Unpublished Doctoral Dissertation. Seoul National University. Seoul, Korea.

Park, S., 2017. An exploratory study on the meaning of visual scaffolding in teaching and learning contexts. Educational Technology International, 18 (2), pp.215-247.

Park, S., 2019. A developmental study on a SPAT design model for mobile learning. Educational Technology Research and Development, 67 (1), pp.123-159.

Park, S. and Rha, I., 2018. Effect of mobile SPAT on learning. In proceedings of the IAFOR(International Academic Forum) conference on education, Dubai, UAE, February 16-18.

Park, S., Rha, I., Byun, H., and Kim, T., 2010. The effect of visual scaffolding and visualization tendency on web-based problem solving. Proceedings of Association for the Advancement of Computing in Education(AACE). Penang, Malaysia. May 19-22.

Pea, R. D., 2004. The social and technological dimensions of scaffolding and related theoretical concepts for learning, education, and human and activity. The Journal of Learning Science, 13 (3), pp.423-451.

Peeck, J., 1993. Increasing picture effects in learning from illustrated text. Learning and Instruction, 3 (3), pp. 227-238.

Quintana, C., Krajcik, J., and Soloway, E., 2002. Scaffolding design guidelines for learner-centered software environments. Paper presented at the annual meeting of the American Educational Research Association(AERA), New Orleans, LA.

Quintana, C., Reiser, B. J., Davis, E. A., Krajcik, J., Fretz, E., Duncan, R. G., Kyza, E. Edelson, D., and Soloway, E., 2004. A scaffolding design framework for software to support science inquiry. The Journal of the Learning Sciences, 13 (3), pp.337-386.

Reigeluth, C. M., 1983. Instructional design: What is it and why is it? In C. M. Reigeluth, eds. Instructional design theories and models: An overview of their current studies. Hillsdale, NJ: Lawrence Erlbaum.

Rha, I., Choi, H., and Choi, S., 2009. A Study on Development of Visualization Tendency Measurement and its Validation. Proceedings of Association for the Advancement of Computing in Education(AACE). Vancouver, BC. Canada. October 26-30. 
Rha, I., and Park, S., 2010. The effect of visual and verbal scaffolds on web-based problem solving performance. Educational Technology International, 11 (2), pp.97-114.

Riding, R. J., and Douglas, G., 1993. The effect of cognitive style and mode of presentation on learning performance. British Journal of Educational Psychology, 63 (2), pp.297-307.

Rubman, C. N., and Waters, H. S., 2000. A, B seeing: The role of reconstructive processes in children's .comprehension monitoring. Journal of Educational Psychology, 92 (3), pp.503-514.

Scaife, M., and Rogers, Y., 1996. External cognition: how do graphical representations work? International Journal of Human-Computer Studies 45 (2), pp.185-213.

Shadiev, R., Hwang, W.Y. and Liu, T.Y., 2018. Investigating the effectiveness of a learning activity supported by a mobile multimedia learning system to enhance autonomous EFL learning in authentic contexts. Educational Technology Research and Development, 66 (4), pp.893-912.

Schmidt, R., Isenberg, T., Jepp, P., Singh, K., and Wyvill, B., 2007. Sketching, Scaffolding, and Inking: A visual history for interactive 3D modeling. Proceedings of NPAR, 23-32, New York, ACM.

Schutt, M., 2003. Scaffolding for online learning environments: Instructional design strategies that provide online learner support. Educational Technology, 43 (6), pp.28-35.

Schwartz, D., and Heiser, J., 2005. Spatial Representation and Imagery in Learning. In R. K. Sawyer, eds. The Cambridge Handbook of the Learning Sciences. (pp.283-298). Cambridge University Press.

Sharma, P. and Hannafin, M. J., 2007. Scaffolding in technology-enhanced learning environments. Interactive learning environments 15 (1), pp.27-46.

Tabak, l., 2004. A complement to emerging patterns of distributed scaffolding. The Journal of the Learning Sciences, 13 (3), pp.305-335.

Urlich, C., 2012. Emerging trends and recent developments in education research. Studia Doctoralia, 1 (1-2), pp.65-84.

Vygotsky, L. S., 1962. Thought and language. Cambridge, MA: MIT Press.

Wileman, R. E., 1993. Visual communicating. Englewood Cliffs, NJ: Educational Technology Publications.

Wood, D., Bruner, J. S., and Ross, G. (1976). The role of tutoring in problem solving. Journal of Child Psychology and Psychiatry, 17(2), pp.89-100. 